\title{
Correspondence
}

\section{Eschew the ACHOO!}

To the Editor

We are grateful to Dr. Abramson for reviewing the aetiology of a sneeze during sedation and the hazard it poses during regional anaesthesia of the head and neck.'

However, we cannot condone the technique described for regional anaesthesia of the eye in the case reported - penetration to a depth of $38 \mathrm{~mm}$ portends an increased hazard of complications. An anatomical study of the orbit demonstrated that needle insertion to a depth of $38 \mathrm{~mm}$ could penetrate the optic nerve in $11 \%$ of the population. ${ }^{2}$ Large series of successful regional eye blocks with shorter $31 \mathrm{~mm}$ needles having low complication rates ${ }^{3.4}$ have led to widespread recommendations to avoid decp injections in the orbit. . $^{5,6}$

We prefer a more lateral entry point for inferotemporal needle insertion ${ }^{7}$ than the classic injunction of the lateral third and medial two-thirds of the lower orbit ridge.' A more lateral needle path avoids injection into the inferior oblique and inferior rectus muscles, averting the hazards of myotoxicity and diplopia ${ }^{8}$ from muscle degeneration. ${ }^{9}$ We also prefer the use of fine sharp needles $(31 \mathrm{~mm} 27$ gauge) that are less painful for the patient, obviating the need for sedation. Although a cadaveric study documented a higher pressure was required to penetrate the globe with a blunt versus sharp needle, ${ }^{10}$ glober perforation by a blunt needle may be more often associated with retinal detachment and poor visual activity. "The use of sharp needles for orbital anaesthesia is supported in the literature. ${ }^{12,13}$

A misadventure was skillfully avoided in the case reported when the needle was withdrawn before a sneeze occurred; we submit that when shorter needles are used and sedation is avoided through the use of sharp needles, the disasterous complications so nearly missed in the reported case could be more securely avoided.

\section{Tom Elwood MD}

Rock G. Loken MD

Robert C. Hamilton $\mathrm{MB} B \mathrm{BCh}$

Department of Anaesthesia

Foothills Hospital

140329 th St NW

Calgary, Alberta, T2N 2T9

\section{REFERENCES}

1 Abramson $D C$. Sudden unexpected sneezing during the insertion of peribulbar block under propofol sedation. Can J Anaesth 1995; 42: 740-3.

2 Katsev DA, Drews RC, Rose BT. An anatomic study of retrobulbar needle path length. Opthalmology $1989 ; 96$ : 1221-4.

3 Fry RA, Henderson J. Local anaesthesia for eye surgery. The peri-ocular technique. Anaesthesia 1989; 45: 14-7.

4 Davis $D B$ 2nd, Mandel MR. Efficacy and complication rate of 16,224 consecutive peribulbar blocks. A prospective multicenter study. J Cataract Refract Surg 1994; 20 : 327-37.
5 Donlon JV. Anesthesia in eye, ear, nose, and throat surgery. In: Miller RD (Ed.). Anesthesia, 4th ed. New York: Churchill Livingstone Inc., 1994: 2176.

$6 \mathrm{Zahl} \mathrm{K}$. Selection of techniques for regional blockade of the eye and adnexa. In: McGoldrick KE. Anesthesia for opthalmic and otolaryngologic surgery. Philadelphia: W.B. Saunders Co., 1992: 240.

7 Hamilton $R C$. Techniques of orbital regional anaesthesia. Br J Anaesth 1995; 75: 88-92.

8 Hunter DG, Lam GC, Guyton DL. Inferior oblique muscle injury from local anesthesia for cataract surgery. Ophthalmology 1995; 102: 501-9.

9 Carlson BM, Emerick S, Komorowski TE, Rainin EA, Shepard $B M$. Extraocular muscle regeneration in primates. Local anesthetic-induced lesions. Ophthalmology 1992; 99: 582.

10 Waller SG, Taboada J, O'Connor $P$. Retrobulbar anesthesia risk. Do sharp needles really perforate the eye more easily than blunt needles? Ophthalmology 1993; 100: 506-10.

11 Grizzard WS, Kirk NM, Pavan PR, Antworth MV, Hammer $M E$, Roseman $R L$. Perforating ocular injuries caused by anesthesia personnel. Ophthalmology 1991; 98: 1011-6.

12 Vivian AJ, Canning $C R$. Scleral perforation with retrobulbar needles. Eur J Implant Refract Surg 1993; 5: 39-41.

13 Wong $D H$. Regional anaesthesia for intraocular surgery. Can J Anaesth 1993; 40: 635-57.

\section{REPLY}

Thank you for allowing me the opportunity to reply to Drs. Elwood, Loken and Hamilton; their reference to an $11 \%$ possibility of damaging the optic nervel is certainly nothing to be sneezed at! Indeed, this high possibility is quoted in other studies despite the existence of only one case report of peribulbar injection leading to optic nerve injury. ${ }^{2}$ However, I agree with the criticism. Dr. Hamilton and his group have undoubtedly shown the safety of peribulbar injection with needle penetration to a depth of $25 \mathrm{~mm}$, demonstrating (in over 5700 patients) no optic nerve injury. ${ }^{3}$ Despite the widespread use of $38 \mathrm{~mm}$ needles, current recommendations ${ }^{4}$ agree with their suggested depth of penetration of not greater than $31 \mathrm{~mm}$.

While I agree that fine sharp needles are less painful for the patient and thus easier to place without sedation, personal experience of oblivious globe penetration has led me back to the blunt needle. A fine needle may be used to place a skin weal through which the larger needle may be passed later. If. as suggested, ${ }^{5}$ the injection is warmed, alkalinised, and injected slowly, minimal patient discomfort is encountered and sedataion may be minimised or avoided altogether. But then, how would we ever have discovered the ACHOO syndrome?!

D.C. Abramson MB FFA

Houston, Texas

REFERENCES

I Katsev DA, Drews RC, Rose BT. An anatomic study of 
retrobulbar needle path length. Ophthalmology 1989; 96 : 1221-4.

2 Wong $D H$. Regional anaesthesia for intraocular surgery. Can J Anaesth 1993; 40: 635-57.

3 Hamilton RC, Gimbel HV, Strunin L. Regional anaesthesia for 12,000 cataract extraction and intraocular lens implantation procedures. Can J Anaesth 1988; 35: 61'5-23

4 Demediuk OM, Dhaliwal RS, Papworth DP, Devenyi RG, Wong CT. A comparison of peribulbar and retrobulbar anesthesia for vitrcoretinal surgical procedures. Arch Ophthalmol 1995; 113: 908-13.

5 Abramson $D C$. Sudden unexpected sneezing during the insertion of peribulbar block under propofol sedation. Can J Anaesth 1995; 42: 740-3.

\section{Postoperative pain management - beyond basics}

\section{To the Editor:}

Butscher $e t$ al. ${ }^{\prime}$ report a technique for intramuscular dosing with morphine based on observed patient requirements in the PACU. They state the technique provides "efficacious and relatively inexpensive postoperative analgesia." Those comments are echoed in an editorial by Moote. ${ }^{2}$ The conclusions of the study relating to efficacy and expense of $i m$ injections, and the related editorial comments (which also include the issuc of safety) should be viewed with caution.

In the Butscher study, it does not appear that patient reports of pain were obtained under standard conditions. An important distinction should be made between rest pain, which is generally easy to control, and incident pain such as that associated with deep breathing, ambulation, or maintenance of a normal range of motion after replacement of a major joini. Adequate control of incident pain is considerably more difficult to achieve than control of rest pain: What kind of pain was studied by Butscher et al.: rest pain, incident pain, or undifferentiated pain? Unless patients were specifically asked to rate their incident pain, the probability is that rest pain was usually reported. Intramuscular injections are not well suited to the control of incident pain. The best than can be done is to regularize the medicating schedule as suggested by Dr. Moote in her editorial. Such an approach may still produce inadequate analgesia for incident pain while imposing excessive doses of medication, and resultant side effects, during periods of rest. PCA offers the advantage of allowing patients to meet their individual and changing needs, including premedication for incident pain. Well-managed epidural analgesia produces more effective analgesia than im injections both at rest and with stimulation.

The authors provided no information to support their conclusion that im injections were "relatively inexpensive." To what are the authors comparing the cost of in injections, and what information do they offer to support the claim? The factors that contribute to the cost of providing pain relief are numerous and difficult to study. Some of them extend well beyond the period of time when a pain relief modality is used, and may be related to such issues as efficacy and safety of the therapy. Although a technique may be incxpensive to provide, if postoperative complications such as fevers, atelectasis, pneumonia, or thrombo-embolic complications are more frequent as a consequence of less effective pain relief, the perccived cost savings may be overshadowed by the costs associated with evaluating and treating those problems. Even a single adverse event involving mortality or serious morbidity associated with providing analgesia can cost millions of dollars.

Dr. Moote in her editorial states that Butscher's study describes an approach to pain management which is "simple, safe and effective." The safety of the approach was not established by this study. Only 53 patients received im morphine. A much larger study would be needed to determine safety when events such as respiratory depression ordinarily occur only rarely. Butscher et al. observed one case of respiratory depression and one case of sedation requiring the patients to be withdrawn from the study. Fourteen additional patients had a respiratory rate less than 12 breaths $\cdot \min ^{-1}$. These observations followed iv morphine titration in the PACU.

There are liabilities to $\mathrm{im}$ injections that were not mentioned by the authors of this study or by Dr. Moote. First, intramuscular injections are painful, traumatic and aversive to many patients. It is not only children who may choose to suffer their incisional pain rather than experience another unpleasant procedure. Second, although it is true that in a perfect world, nurses might be able to check on the adequacy of pain relief on a regular basis (e.g., every hour), in reality, such regular cvaluation is sometimes not possible. Even if nurses were not hesitant to call surgeons for help with problems of inadequate analgesia, the interest and expertise that could be expected in response to such calls is undetermined. One of the advantages of PCA is the independence it affords patients. Medication remains available during periods when the nurse and/or physician may not be.

There is no doubt that costs of medical care must be justified. I support the use of less expensive methods when they provide an acceptable alternative to more costly ones. The question is, who should be the judge of acceptability? We might do well to defer to the consumer, i.e., the patients (who also elect government representatives). If asked which elements of medical care they would be least willing to give up, it is my contention that adequate, safe, pain relief would be at or near the top of the list. I do not think that intramuscular injections, even when used optimally, would be considered an acceptable alternative to more modern methods by a wellinformed general public.

Dr. Moote correctly states that "physician billing is an integral part of any pain service and may be the most expensive component." Although the old economic adage "you get what you pay for" is still valid, I wonder if it is time to give our patients "more than they pay for." Is it timely for us to considcr offering our professional services to our patients in pain after surgery without additional charges? With that approach, modern techniques for postoperative pain management would be made immediately more affordable and our credibility as a specialty which is dedicated both to quality of care and fiscal responsibility would be enhanced. I recognize this would present a major redefinition of our specialty's "job description" but, as Dr. Moote points out, "in the race to reduce cost, we must strive to protect essential services for patients who need them most."

\section{Brian Ready MD FRCPC}

Department of Ancsthesiology

University of Washington

Box 356540

Seattle, WA 98195-6540 USA 